\title{
Review Article \\ Can Molecular Biomarkers Change the Paradigm of Pancreatic Cancer Prognosis?
}

\author{
Javier Martinez-Useros and Jesus Garcia-Foncillas \\ Translational Oncology Division, OncoHealth Institute, Health Research Institute, University Hospital Fundación Jiménez Díaz-UAM, \\ Madrid, Spain
}

Correspondence should be addressed to Javier Martinez-Useros; javier.museros@oncohealth.eu

Received 9 June 2016; Revised 28 July 2016; Accepted 3 August 2016

Academic Editor: Hanlin L. Wang

Copyright (C) 2016 J. Martinez-Useros and J. Garcia-Foncillas. This is an open access article distributed under the Creative Commons Attribution License, which permits unrestricted use, distribution, and reproduction in any medium, provided the original work is properly cited.

\begin{abstract}
Pancreatic ductal adenocarcinoma is one of the most lethal types of tumour, and its incidence is rising worldwide. Although survival can be improved when these tumours are detected at an early stage, this cancer is usually asymptomatic, and the disease only becomes apparent after metastasis. The only prognostic biomarker approved by the FDA to date is carbohydrate antigen 19-9 (CA199); however, the specificity of this biomarker has been called into question, and diagnosis is usually based on clinical parameters. Tumour size, degree of differentiation, lymph node status, presence of distant metastasis at diagnosis, protein levels of KI-67 or Creactive protein, and mutational status of P53, KRAS, or BRCA2 are the most useful biomarkers in clinical practice. In addition to these, recent translational research has provided evidence of new biomarkers based on different molecules involved in endoplasmic reticulum stress, epithelial-to-mesenchymal transition, and noncoding RNA panels, especially microRNAs and long noncoding RNAs. These new prospects open new paths to tumour detection using minimally or noninvasive techniques such as liquid biopsies. To find sensitive and specific biomarkers to manage these patients constitutes a challenge for the research community and for public health policies.
\end{abstract}

\section{Introduction}

Pancreatic ductal adenocarcinoma (PDAC) is the fourth leading cause of cancer death in both sexes in the USA. In 2014, the number of deaths from PDAC in the USA was 39,590 , and PDAC is the cause of 227,000 deaths per year worldwide $[1,2]$. Furthermore, a statistical analysis carried out from 2001 to 2010 indicates that death rates are rising [3]. Survival can be improved when tumours are detected at an early stage: it has been reported that 5-year survival rate is $50 \%$ when tumours are $<2 \mathrm{~cm} \mathrm{[4]} \mathrm{and} \mathrm{close} \mathrm{to} 100 \%$ for tumours $<1 \mathrm{~cm}$ [5]. However, PDAC is usually asymptomatic, and the disease only becomes apparent after the tumour invades surrounding tissues or metastasises to distant organs [6].

Cigarette smoking is the leading preventable extragenetic cause of PDAC and is believed to account for $20 \%$ of PDAC cases [7]. Smoking shows a dose-related effect on tumour development, increasing the risk of PDAC by
25\% compared to nonsmokers [8]. Chronic pancreatitis also increases the risk of PDAC, causing a cumulative risk of $4 \%$ after 20 years [9]. Additionally, diabetes was recently considered a potential and early symptom of PDAC, as the disease is observed in approximately $30 \%$ of all patients [10]. Also, several studies have investigated the specific role of infectious agents that affect PDAC. Of these, the strongest association has been reported for Helicobacter pylori: a metaanalysis comprising seven studies found that presence of Helicobacter pylori was correlated with as much as a $65 \%$ increased risk of developing PDAC [11, 12].

For the moment, surgical resection remains the best option to manage PDAC, and survival can be predicted based on the pathological characteristics of the tumour such as $\mathrm{T}, \mathrm{N}$, and $\mathrm{M}$ stage, grade of differentiation, or positive resection margins [13]. However, there is a lack of validated postsurgical prognostic or predictive markers to be used in patient management [14]. In this context, several reports of prognostic molecular biomarkers have appeared in the 


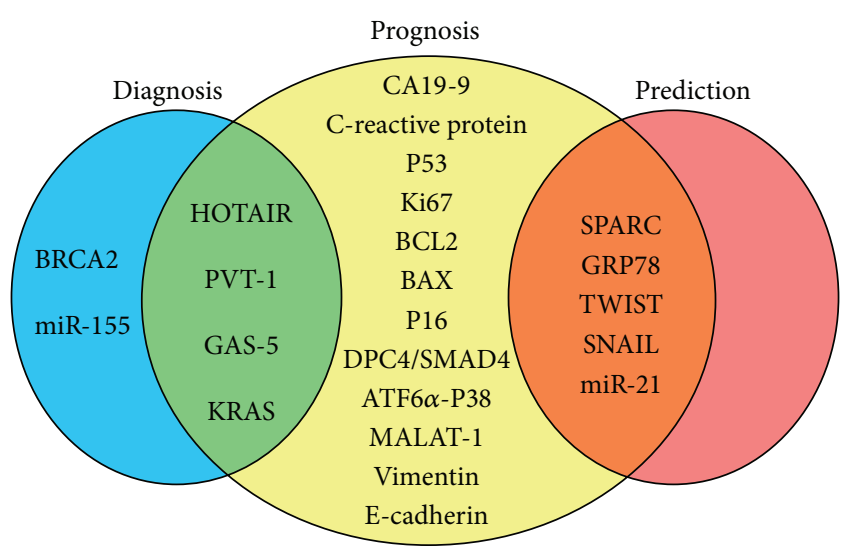

FIGURE 1: Molecular biomarkers in PDAC. Most of the molecular biomarkers may have multiple functions. Some prognosis biomarkers could be used both for diagnosis (HOTAIR, PVT-1, GAS-5, and KRAS) and for predicting treatment response (SPARC, GRP78, TWIST, SNAIL, and miR-21).

literature. They include SMAD4, MUC1, and also predictive markers including SPARC, HuR, or members of the BRCA2 family [15-17]. However, new high throughput genetic profiling platforms have become a useful tool for analysing whole DNA, RNA, and other factors that may or may not be translated into protein, mainly microRNAs (miRNA). In the era of genomics, transcriptomics, and proteomics, these methodologies have helped to elucidate potential biomarkers to manage patients with PDAC.

The NIH Biomarker Working Group defined biomarkers as "a characteristic i.e., objectively measured and evaluated as an indicator of normal biological processes, pathogenic processes or pharmacologic responses to a therapeutic intervention [18]." Biomarkers can be categorised as diagnostic, prognosis, or predictive based on their function; however, some biomarkers may have multiple functions (Figure 1, Table 1). Diagnostic biomarkers are able to identify early high-risk premalignant lesions. Prognostic biomarkers provide information about disease outcome in surgically resected individuals not treated with chemotherapy, radiotherapy, or their combinations. Predictive markers can discriminate between responders to a given treatment and nonresponders.

\section{Biomarkers Based on Clinical Variables}

Very few biomarkers have been introduced in the routine clinical management of PDAC. The most commonly used are based on clinical variables such as ECOG and other variables like levels of CA19-9. The way the disease affects a patient's daily living abilities is determined according to the ECOG (Eastern Cooperative Oncology Group) classification. ECOG has been considered as an important independent prognostic factor for patient outcome. This system published in 1982 was agreed upon as standard criteria to quantify functionality of cancer patients in terms of their ability to have daily regular and physical activity or provide self-care in order to determine the ability to receive a certain treatment (Table 2) [61]. Several clinical trials demonstrated that poor ECOG is an independent negative prognostic factor in PDAC. Thus, a baseline ECOG value of 2 was reported as an independent adverse prognostic factor for survival $(\mathrm{HR}=1.735 ; P<0.001)$ in one study that compared gemcitabine in combination with oxaliplatin to gemcitabine alone [19]. A phase III clinical trial comparing gemcitabine in combination with tipifarnib to gemcitabine plus placebo revealed ECOG 0 to be a better prognostic factor associated with survival $(\mathrm{HR}=0.53 ; P<$ 0.001) [20]. Recently, high ECOG $(\mathrm{HR}=2.26 ; P=0.001)$ was associated with poorer overall survival in patients treated with FOLFOXIRI as a first-line treatment [21].

In addition to these, new molecular biomarkers have appeared which can dissect disease information. Deletions, mutations, translocations, amplifications, overexpression or downregulation of DNA, RNA, protein, or noncoding RNA factors are the most commonly described in scientific reports. A selection of these molecular biomarkers is summarised below to broaden the understanding of their functions and potential clinical uses.

\section{Carbohydrate Antigen 19-9}

Elevated serum levels of carbohydrate antigen 19-9 (CA19-9) have been confirmed as a prognostic biomarker for PDAC, since patients with high values for this antigen presented statistically significant poor survival. In one study, it was suggested that elevated preoperative serum levels of CA199 could predict time to recurrence after surgery $(P=$ 0.0049) [22]. To date, the only FDA-approved biomarkers for resectable PDAC are preoperative levels of CA19-9, and this biomarker is used for both early detection and establishing prognosis $(P=0.003)$ [23]. CA19-9 shows higher sensitivity for PDAC [62] compared to carcinoembryonic antigen (CEA), carbohydrate antigen 50 (CA-50), and DUPAN-2 $[63,64]$. However, the specificity of this marker has been called into question since other clinical events such as biliary obstruction can increase CA19-9 serum levels [65] and because up to $10 \%$ of the population cannot synthesise this antigen [66]. Nevertheless, CA19-9 is currently considered the best serum marker for PDAC [67].

\section{C-Reactive Protein}

C-reactive protein is a protein produced by the liver as part of the systemic inflammatory response and has been considered a useful biomarker based on detection of inflammation $[68,69]$. High concentration of C-reactive protein has been previously associated with shorter survival in unresectable PDAC [24, 25]. Concerning resectable PDAC, it has been reported that C-reactive protein levels $\leq 10 \mathrm{mg} / \mathrm{L}$ after surgery predicted better disease outcome $(P<0.001)$. However, elevated preoperative $\mathrm{C}$-reactive protein associated with higher tumour size $(P<0.05)$, vascular invasion $(P<0.05)$, and poor differentiation $(P<0.05)$ [26]. In another study, high concentration of C-reactive protein $(>5 \mathrm{mg} / \mathrm{L})$ associated with a significantly reduced survival in unresectable PDAC $(P=0.027)$ independently of biliary tract obstruction, although no association was found in resectable cohort [27]. Recently, it has been reported that the ratio between 


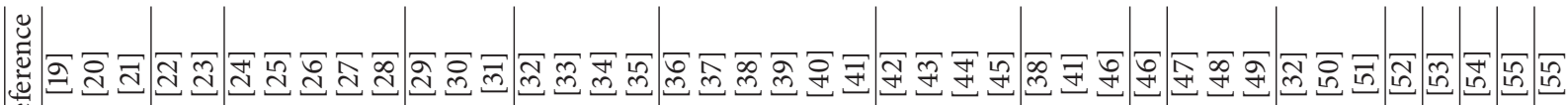
$\approx$

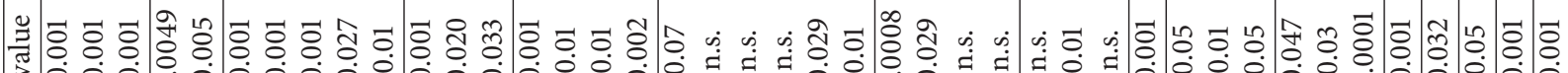

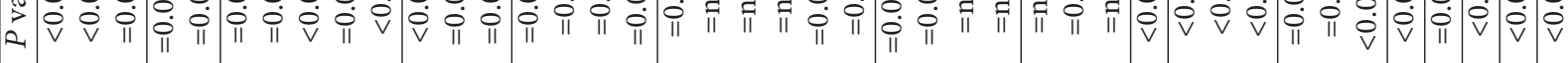
(2)

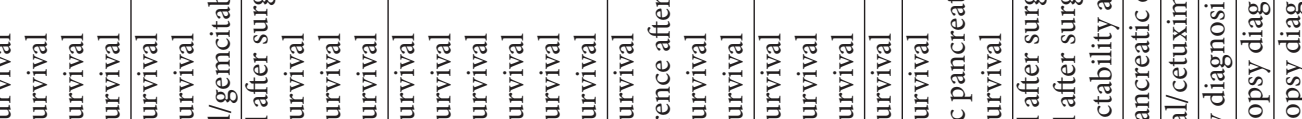
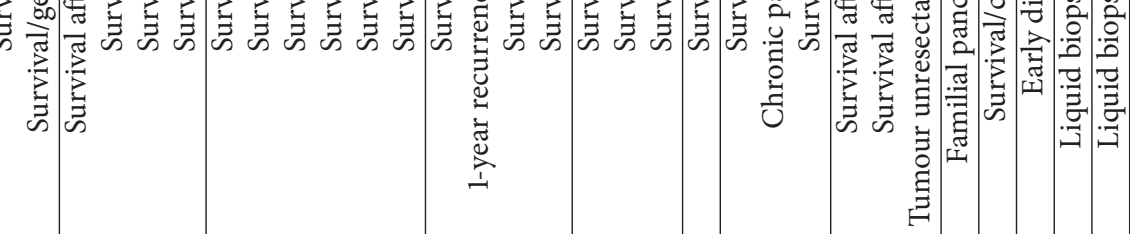

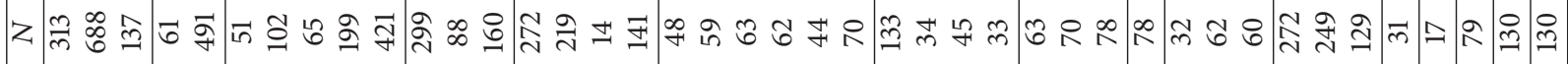

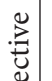

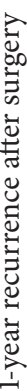

की के

苛艺

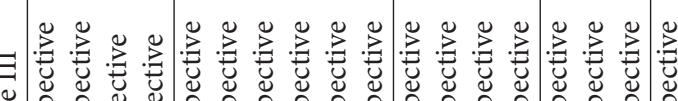

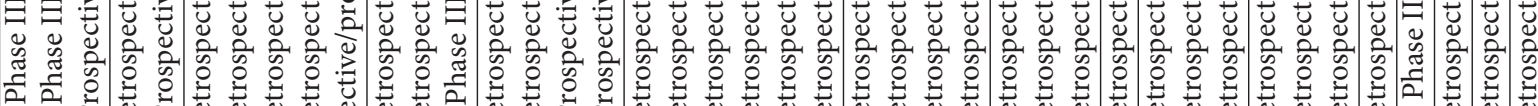

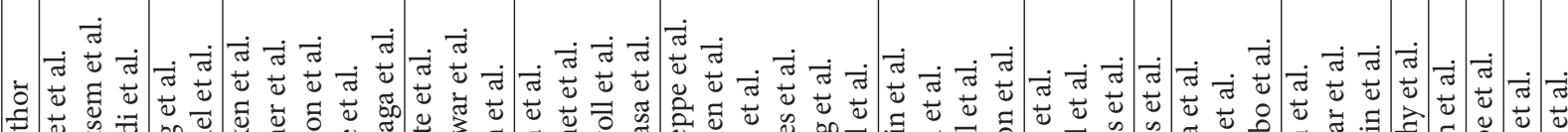

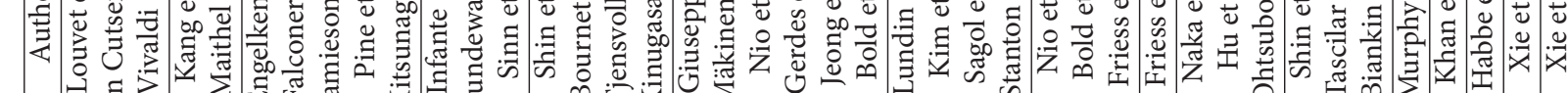

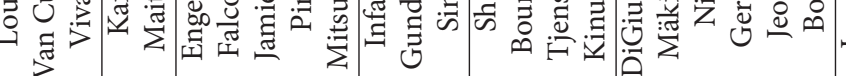

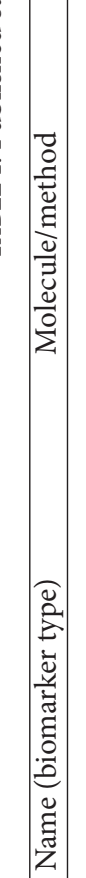

\section{코 켸큐}

苟

II III

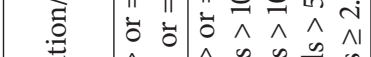

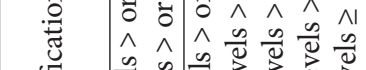

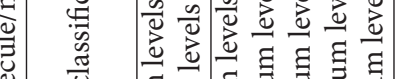

$\stackrel{2}{2}$

.

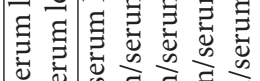

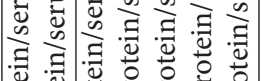

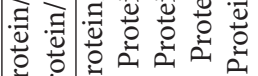
要

帛

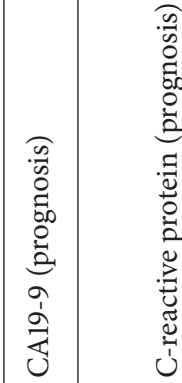

क्ष

릴

¿
垔

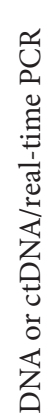

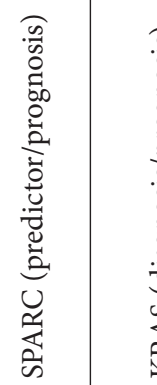

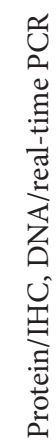

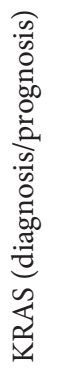

a

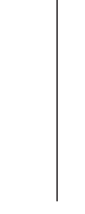

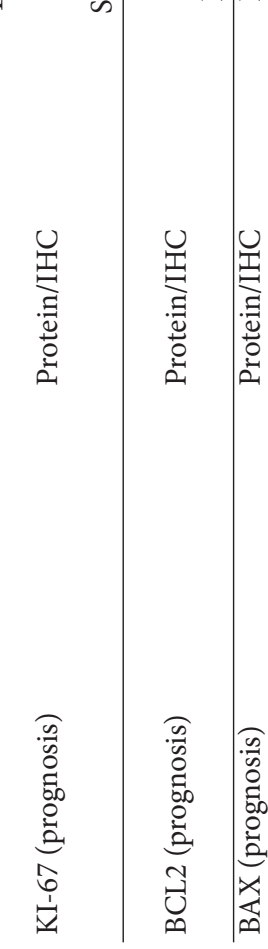

$\approx$

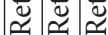

항

荘

皮

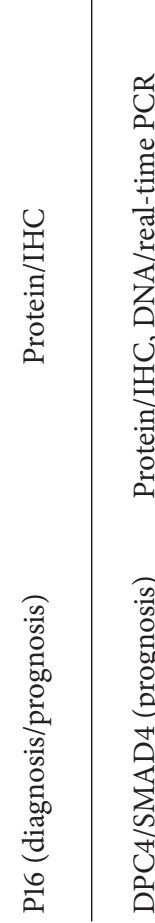

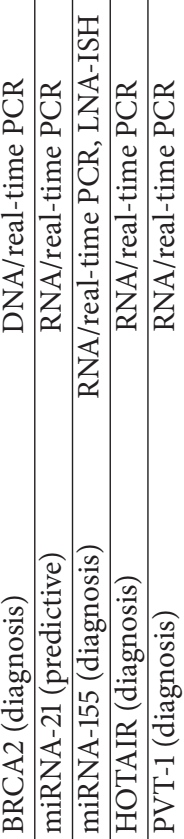




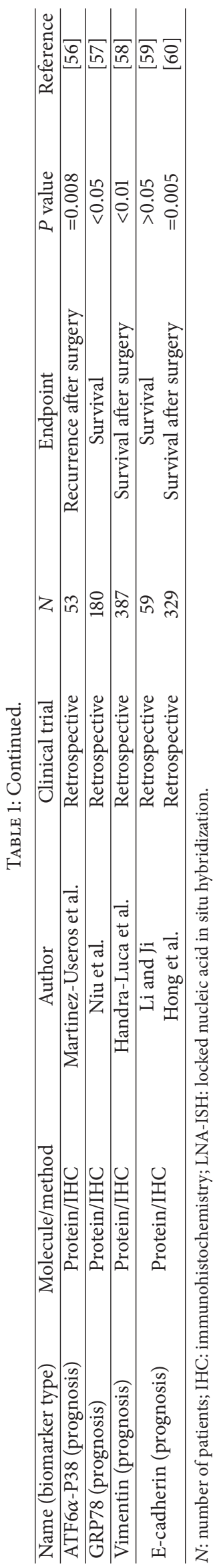


TABLE 2: Eastern cooperative oncology group classification of performance status.

\begin{tabular}{|c|c|}
\hline Grade & ECOG, performance status \\
\hline 0 & Fully active, able to carry on all predisease performance without restriction \\
\hline 1 & $\begin{array}{c}\text { Restricted in physically strenuous activity but ambulatory and able to carry out work of a light or sedentary nature, for } \\
\text { example, light house work, office work }\end{array}$ \\
\hline 2 & $\begin{array}{c}\text { Ambulatory and capable of all self-care but unable to carry out any work activities; up and about more than } 50 \% \text { of waking } \\
\text { hours }\end{array}$ \\
\hline 3 & Capable of only limited self-care; confined to bed or chair more than $50 \%$ of waking hours \\
\hline 4 & Completely disabled; cannot carry on any self-care; totally confined to bed or chair \\
\hline 5 & Dead \\
\hline
\end{tabular}

C-reactive protein and albumin is a significant prognostic biomarker for resectable PDAC after operation $(P=0.035)$, together with TNM classification $(P=0.003)$ [70]. Furthermore, C-reactive protein at low $(<0.5 \mathrm{mg} / \mathrm{L})$, medium $(\geq 0.5$ and $<2.0 \mathrm{mg} / \mathrm{L})$, and high levels $(\geq 2.0 \mathrm{mg} / \mathrm{L})$ is associated with good, moderate, and poor survival, respectively [28].

\section{SPARC}

The secreted protein acidic and rich in cysteine, abbreviated as SPARC, is a crucial glycoprotein for PDAC proliferation, invasion, metastasis, and chemoresistance [71, 72]. In one study, expression of SPARC was not associated with patient prognosis $(P=0.13)$, although the authors report that patients whose tumour stroma expressed SPARC had shorter median survival than patients whose tumour stroma lacked this expression (15 months versus 30 months, resp., $P<$ 0.001) [29]. Another study supports the role of SPARC as a prognostic factor, with a similar median survival to that of the aforementioned study (11.5 versus 25.3 months; $P=0.020$ ) [30]. Further research has associated stromal and cytoplasmic SPARC expression with short survival and poor response to gemcitabine [31].

\section{KRAS}

One of the causes of mutation in KRAS is the uncontrolled activation of RAS via Hedgehog pathway through SMO [73]. However, Hedgehog is not enough to trigger the RAS pathway in pancreatic malignancies [74]. Another factor that interacts and regulates the KRAS variants G12V and G12D is ribonucleoprotein HNRNPA2B1 [75]. PDAC has the highest incidence of KRAS mutation of all types of tumours, and more than $50 \%$ of patients could exhibit this abnormality $[32,76]$; additionally, the KRAS mutation is considered a critical event for the initiation of this type of cancer [77].

The FDA approved Therascreen (Qiagen) and Cobas 480 (Roche) assays to detect KRAS mutations status [78, 79]. One study that compared both methodologies showed $98 \%$ of concordance between them, although Cobas 480 identified other mutations that were not detected by initial Therascreen assay [80]. Apart from real-time PCR-based assays [81,82], other methodologies based on pyrosequencing $[83,84]$ have appeared to detect higher number of KRAS mutations (Table 3).
One study performed with 272 patients with resectable PDAC reported the following incidence in the different KRAS mutations: wild type $46.2 \%$; GAT $31.2 \%$; GTT $14.5 \%$; CGT 5.6\%; TGT 1.7\%; CTG 0.4\%; and AGT 0.4\% [32]. Mutational status is an independent biomarker for PDAC at multiple steps, mainly for diagnosis and prognosis, although some mutations should be taken into consideration as predictive biomarker to specific drugs [85]. Mutation G12D indicates poor prognosis $(\mathrm{HR}=1.44 ; P=0.01)$ [33]. Recently, determination of KRAS was performed in circulating tumour cells (CTCs) or in plasma circulating DNA (ctDNA) to determine PDAC prognosis; the results of this study have confirmed the utility of liquid biopsy as a promising material for diagnosis $[34,35]$.

\section{P53}

The P53 phosphoprotein encoded by the gene TP53 is a nuclear factor that inhibits cell proliferation through activation of apoptosis [86]. TP53 is mutated in 50\% and 75\% of PDAC tumour cells $[87,88]$. Loss of P53 has been argued to be a negative prognostic factor in pancreatic neoplasm [89-91]. However, the relation between TP53 mutation status and clinical outcome is rather controversial, so its role as a prognostic biomarker has yet to be validated [36-40, 92, 93]. P53 overexpression showed a marked trend toward significance when compared to survival $(P=0.07)$; however, its high hazard ratio $(\mathrm{HR}=1.8)$ suggests that it may be a poor prognostic factor for PDAC [36]. Another study showed statistically significant differences in disease-free survival between patients with and without P53 overexpression $(P=$ 0.029), although this comparison failed to reach clinical significance, leading the authors to conclude that they did not have enough evidence in support of P53 as a prognosis factor [40].

\section{KI-67}

$\mathrm{Ki}-67$ is a protein that is not expressed in resting cells, but it is present during all cell cycle phases, including G1, S, G2, and mitosis. This fact makes it an excellent clinical marker for determining the growth fraction of a tumour [94]. Ki67 positive expression has been associated with pathological characteristics such as TNM stage, surgical resectability, or tumour grade in pancreatic cancer [42]. Kim et al. reported 


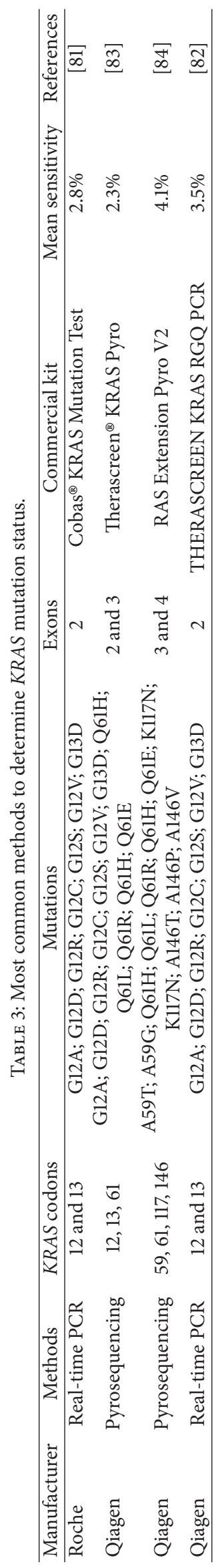


a statistical association between Ki-67 expression and recurrence after surgery within 1 year $(P=0.029)$ [43]. In contrast, this marker, when quantified by immunohistochemistry [37, 44] or by flow cytometry [45], seems not to have any association with survival.

\section{BCL2 and BAX}

BCL2 acts as an inhibitor of mitochondrial apoptosis, while BAX has been reported as a proapoptotic factor. Preclinical studies have concluded that increased BCL2 expression correlated with apoptotic resistance and malignant phenotype in pancreatic cancer $[95,96]$. Interestingly, as opposed to other neoplasms, BCL2 in PDAC has been clinically associated with better outcome and longer survival $[38,41]$. Contrary to these results, another report did not show correlation between BCL2 and survival improvement [46]. On the other hand, the same study suggested BAX expression as a strong indicator of longer survival $(P<0.001)$ even when BAX and BCL2 were found to be overexpressed in pancreatic tumour cells [46]. Thus, it seems that the role of BCL2 in pancreatic cancer progression is still unclear, and further research is needed.

\section{P16}

Encoded by the CDKN2A gene, P16 is a tumour suppressor factor that plays a crucial role in cell cycle regulation [97, 98]. Preclinical studies on pancreatic cancer cell lines and xenografts have reported several alterations concerning P16 that include homozygous deletions, point mutations, and inactivation by P16 promoter methylation [92]; most such alterations are accompanied by loss of the wild-type allele [99]. Clinical studies with PDAC patients support that lack of $\mathrm{P} 16$ protein expression is associated with advanced disease stage and poor survival $(P<0.05)[39,47]$. Furthermore, P16 expression may differentiate chronic pancreatitis from PDAC that frequently lacks P16 [48]. Interestingly, Ohtsubo et al. found $\mathrm{P} 16$ positivity in $77 \%$ of PDAC tumours. However, they settled on an association between $P 16$ mutation or hypermethylation and shorter patient survival $(P<0.05)$ [49]. Concerning associations with clinicopathological characteristics, studies have shown several discrepancies. Loss of P16 expression was associated with lymph node metastasis $(P=$ $0.040)$, more advanced stage $(P=0.015)$ [40], and greater tumour size [49]. On the other hand, loss of P16 is associated with poor differentiation grade $(P<0.01)$ but not with other clinicopathological characteristics, including clinical stage, tumour location, resectability, and survival [48].

\section{DPC4/SMAD4}

DPC4 (Deleted in Pancreatic Cancer 4) is a truncated protein encoded by a mutated form of the SMAD4 gene located in the human chromosome 18. It has been considered a tumour suppressor gene and has been found to be highly mutated in colorectal cancer and PDAC [100]. The signalling pathway triggered by TGF- $\beta$ has become of great interest concerning DPC4. A nonsense mutation in SMAD4 generates a Cterminal truncation of 38 amino acids in the DPC4 protein, and it has been detected in 55\% of patients with PDAC [101]. The mutant DPC4 is unable to be recruited to DNA by transcription factors and thus cannot form transcriptionally active DNA-binding complexes [102]. These mutations activate the RB pathway involved in cellular proliferation [103]. It has been suggested that inactivation of SMAD4 occurs as a late event in neoplastic progression [104]. DPC4 inactivation resulted in a reduction in survival after surgical resection in PDAC $(P=0.047)$ [32]. Tascilar et al. also confirmed that PDAC patients with SMAD4 protein expression had significantly longer survival than those lacking expression of the protein $(P=0.03)$ [50]. Furthermore, the frequency of loss of SMAD4 expression is different in various locations of the hepatobiliopancreatic cancers, so tumour origin may merit consideration analysing this factor [104]. In contrast, another study suggested that preoperative assessment of SMAD4 mutation associated with resectability $(P<0.0001)$ and with improved survival $(P<0.0001)[51]$.

\section{BRCA2}

$B R C A 2$ is a tumour suppressor gene identified as a factor for heritable cancer susceptibility [105]. The role of BRCA2 is focused on regulation of $R A D 51$ recombination in response to DNA damage and regulates sister chromatid cohesion and/or alignment [106]. Initially, BRCA2 mutations were associated with breast and ovarian cancer [107, 108], but these alterations were also associated with risk of familial PDAC. Hahn et al. reported that $19 \%$ of the families they studied (range 7-39\%) had either a mutation or a variant of BRCA2 [109]. Furthermore, the probability of finding a germline mutation of BRCA2 in a PDAC patient is between $6 \%$ and $12 \%$ when the patient has a first-degree relative diagnosed with PDAC [52]. The most common mutations found in pancreatic cancer patients are the 6174delT frameshift mutation, 6158ins T mutation, splice site mutation 16-2A>G, and the splice site mutation $15-1 \mathrm{G}>\mathrm{A}[52,110]$. BRCA2 inactivation has been reported to be a late event in pancreatic tumorigenesis [111] and suffices to initiate PDAC driven by KRAS mutation G12D or disrupted TP53 [112, 113].

It seems that BRCA2 is a high-risk factor for pancreatic cancer development but has not been related to patient outcome or treatment response.

\section{Noncoding RNAs}

Over the last few years, noncoding RNA (ncRNA), especially microRNAs (miRNAs) and long noncoding RNAs (lncRNAs), has become a new diagnostic, prognostic, and predictive tool for pancreatic cancer. Several miRNAs have been related to cell proliferation, invasion, and metastasis, the most relevant of which are miR-21, miR-155, and miR-34. The overexpression of miR-21 was associated with a shorter disease-free survival in patients who received adjuvant gemcitabine after surgical resection [114], and miR-21 overexpression predicts resistance to 5-fluorouracil [115]. Furthermore, high miR-21 levels in plasma were associated with poor outcome in those patients treated with induction chemotherapy followed by chemoradiotherapy [53]. MiR-155 was found 
to be overexpressed in PDAC and could be used as an early diagnostic biomarker [54]. Moreover, miR-155 represses expression of nuclear protein 1 induced by P53 (TP53INP1), and it has been shown how its restoration inhibits PDAC tumour development [116]. Pang et al. reported that miR155 is able to reprogram normal fibroblasts into pancreatic cancer-associated fibroblasts [117]. These findings highlight the great potential of miR-155 as a future drug target. MiR-34 is able to restore partial activity of P53 in P53-deficient human pancreatic cancer cells [118].

HOTAIR, PVT-1, MALAT-1, and GAS5 are some of most widely studied lncRNAs in pancreatic cancer. Concerning HOTAIR, its overexpression has been described as a poor prognostic factor in PDAC and recently has been proposed as a salivary biomarker for early diagnosis with PVT-1 expression. Surprisingly, both lncRNAs were downregulated after surgical resection, which suggests their potential for use as tumour recurrence biomarkers after operation [55]. MALAT1 is potential oncogenic lncRNA involved in proliferation, migration, and invasion [119] and promotes undifferentiated phenotype of pancreatic tumour cells [120]. GAS5 (growth arrest-specific 5) is a potential tumour suppressor factor that negatively regulates CDK6 and is significantly decreased in PDAC tissues compared to untransformed tissues [121].

All the aforementioned miRNAs and lncRNAs could serve as diagnostic and prognostic factors, complementing clinical and pathological parameters in the effort to predict the outcome of patients with pancreatic cancer. Moreover, these factors could be quantified from a whole panel and detected from biofluids, thus making them easily implemented in routine clinical diagnosis [122].

\section{Endoplasmic Reticulum Stress Response Proteins}

The main functions of endoplasmic reticulum (ER) include synthesis, folding, and modification of proteins [123]. ER stress is induced by glucose deprivation, oxidative stress, or infection. These phenomena lead to accumulation of unfolded or misfolded proteins in the ER lumen and trigger pancreatic cell dysfunction and apoptosis [124]. To counteract ER stress and induce survival, a response mechanism has emerged [125]. ATF6 $\alpha$ and GRP78 are proteins that are needed to induce response to ER stress. In normal conditions, ATF $6 \alpha$ is linked to GRP78; however, in conditions of ER stress, which are critical for pancreatic cells, both proteins dissociate. ATF6 $\alpha$ is activated in Golgi apparatus [126], migrates to the nucleus, and transcribes survival genes to neutralise ER stress, avoiding apoptosis and promoting cell survival $[127,128]$. Furthermore, ATF6 $\alpha$ is considered an important component in the VEGF-induced vascularization and induces tumour cell survival and angiogenesis [129]. Recently, our group reported a protein expression signature based on high expression of ATF $6 \alpha$ and low expression of P38 as a poor prognosis biomarker associated with shorter time to recurrence after surgery for resectable PDAC [56]. GRP78 is a member of the heat-shock protein 70 (HSP70) family and acts as a chaperone that promotes cell proliferation, invasion, metastasis, and drug resistance in multiples types of cancer [130]. In PDAC, GRP78 has been suggested as a poor prognosis biomarker due to its role in proliferation, migration, and invasion of tumour cells [57] and as a predictive factor for chemoresistance to gemcitabine-based treatment [131]. Such findings open possibilities for new therapeutic strategies based on blocking the activity of GRP78.

\section{Epithelial-to-Mesenchymal Transition Factors}

Epithelial-to-mesenchymal transition (EMT) involves the changes that allow conversion from epithelial-to-mesenchymal-like phenotype [132]. In pancreatic tumours, an increased number of EMT positive cells are associated with poor survival [133]. It is one of the phenomena that subserve stimulation of tumour cells to metastasise to distant organs in the early stages of disease $[134,135]$. Some of the crucial factors involved in EMT are TWIST and SNAIL [135-137]. These two factors are necessary for initiation and progression of primary PDAC, their downregulation has been reported to increase survival in preclinical models, and they have also been reported to confer sensitivity to gemcitabine and irradiation [138-142]. However, knockout of these EMT factors does not reduce metastasis in PDAC [138]. On the other hand, vimentin and E-cadherin are also considered significant proteins associated with EMT. Vimentin expression in tumour cells is a sign of mesenchymal differentiation [143] and then associated with shorter survival [144]. In fact, vimentin expression in tumour cells from resected PDAC patients is an indicator of poor outcome $(P<$ $0.01)$ and was associated with poorly differentiated tumour phenotype $(P<0.01)$ [58]. The lack of E-cadherin expression is linked to both poor differentiation tumour histology and poor outcome in PDAC patients $[59,145]$. In one study, partial and complete loss of E-cadherin expression showed statistically significant association with poor survival of PDAC patients $(P=0.009$ and $P=0.005$, resp. $)$ [60]. These findings suggest that some proteins involved in EMT could be considered as biomarkers of poor prognostic in PDAC and subsequently be potentially used to design target-specific drugs in the near future.

\section{Conclusions}

PDAC generally arises from other neoplasms, including pancreatic intraepithelial and intraductal papillary mucinous and mucinous cystic neoplasms [146]. An early diagnosis and the possibility of resection are the milestones for management of these aggressive neoplasms. To date, both diagnosis and prognosis are based on clinicopathologic parameters like tumour size, grade of differentiation, lymph node status, or presence of distant metastasis at diagnosis [13]. Recent advances in translational research are scarcely implemented in routine clinical practice, and only those patients with high risk for development of PDAC gain access to genetic screening [147].

After surgical resection, there are no validated prognostic or predictive markers to be used in patient management [14]. Used widely, CA19-9 is the only FDA-approved biomarker 
in PDAC [23]. By contrast, its low specificity brings a high number of false positives, which has caused its utility to be called into question, and its use is restricted to detection of recurrence after operation [148]. Recently, a three-marker signature based on levels of CA19-9, IGF-1, and albumin has shown a sensitivity of $93.6 \%$ and specificity of $95 \%$ when differentiating PDAC patients from other pancreatic diseases [149].

Novel molecular biomarkers must allow for quantification by means of minimally or noninvasive techniques. New molecules detected in liquid biopsies will be used to diagnose PDAC patients and will replace single markers with multimarker panels (Figure 1) [122].

Protein detection has been the gold-standard methodology for pathological diagnosis. Nowadays, immunohistochemistry is losing favour relative to qRT-PCR, and it shows that in situ hybridisation, microarray, and deep-sequencing will be considered the best tools for pathological diagnosis in the future (Table 1).

On the other hand, biomarkers studies sometimes lead to controversial results. Therefore, new biomarkers and larger validation cohorts are required. In addition, only biomarkers that combine high-sensitivity and specificity and being highly cost-effective will be incorporated in healthcare systems.

\section{Competing Interests}

The authors declare that they have no competing interests.

\section{Acknowledgments}

The authors thank Oliver Shaw (IIS-FJD) for editing the manuscript for English usage, clarity, and style.

\section{References}

[1] R. L. Siegel, K. D. Miller, and A. Jemal, "Cancer statistics, 2015," CA: A Cancer Journal for Clinicians, vol. 65, no. 1, pp. 5-29, 2015.

[2] S. Raimondi, P. Maisonneuve, and A. B. Lowenfels, "Epidemiology of pancreatic cancer: an overview," Nature Reviews Gastroenterology and Hepatology, vol. 6, no. 12, pp. 699-708, 2009.

[3] R. Siegel, J. Ma, Z. Zou, and A. Jemal, "Cancer statistics, 2014," CA: A Cancer Journal for Clinicians, vol. 64, no. 1, pp. 9-29, 2014.

[4] S. Egawa, K. Takeda, S. Fukuyama, F. Motoi, M. Sunamura, and S. Matsuno, "Clinicopathological aspects of small pancreatic cancer," Pancreas, vol. 28, no. 3, pp. 235-240, 2004.

[5] J. Ariyama, M. Suyama, K. Satoh, and J. Sai, "Imaging of small pancreatic ductal adenocarcinoma," Pancreas, vol. 16, no. 3, pp. 396-401, 1998.

[6] D. P. Kelsen, R. Portenoy, H. Thaler, Y. Tao, and M. Brennan, "Pain as a predictor of outcome in patients with operable pancreatic carcinoma," Surgery, vol. 122, no. 1, pp. 53-59, 1997.

[7] A. Blackford, G. Parmigiani, T. W. Kensler et al., "Genetic mutations associated with cigarette smoking in pancreatic cancer," Cancer Research, vol. 69, no. 8, pp. 3681-3688, 2009.

[8] Y. Lin, A. Tamakoshi, T. Kawamura et al., "A prospective cohort study of cigarette smoking and pancreatic cancer in Japan," Cancer Causes and Control, vol. 13, no. 3, pp. 249-254, 2002.

[9] A. B. Lowenfels, P. Maisonneuve, G. Cavallini et al., "Pancreatitis and the risk of pancreatic cancer," The New England Journal of Medicine, vol. 328, no. 20, pp. 1433-1437, 1993.
[10] S. T. Chari, C. L. Leibson, K. G. Rabe et al., "Pancreatic cancer-associated diabetes mellitus: prevalence and temporal association with diagnosis of cancer," Gastroenterology, vol. 134, no. 1, pp. 95-101, 2008.

[11] X.-Z. Chen, R. Wang, H.-N. Chen, and J.-K. Hu, "Cytotoxinassociated gene A-negative strains of Helicobacter pylori as a potential risk factor of pancreatic cancer: a meta-analysis based on nested case-control studies," Pancreas, vol. 44, no. 8, pp. 1340-1344, 2015.

[12] M. Venerito, R. Vasapolli, T. Rokkas, and P. Malfertheiner, "Helicobacter pylori and gastrointestinal malignancies," Helicobacter, vol. 20, supplement 1, pp. 36-39, 2015.

[13] H. Manuel, "Pancreatic cancer," The New England Journal of Medicine, vol. 362, no. 17, pp. 1562-1617, 2010.

[14] A. Stathis and M. J. Moore, "Advanced pancreatic carcinoma: current treatment and future challenges," Nature Reviews Clinical Oncology, vol. 7, no. 3, pp. 163-172, 2010.

[15] Z. V. Fong and J. M. Winter, "Biomarkers in pancreatic cancer: diagnostic, prognostic, and predictive," Cancer Journal, vol. 18, no. 6, pp. 530-538, 2012.

[16] D. N. Reddy, P. V. Sriram, G. Das, and G. V. Rao, "Endoscopic treatment of pancreatic disorders," Tropical Gastroenterology, vol. 22, no. 3, pp. 149-154, 2001.

[17] Q. Wang, Q. Ding, Z. Dong, R. A. Ehlers, and B. M. Evers, "Downregulation of mitogen-activated protein kinases in human colon cancers," Anticancer Research, vol. 20, no. 1, pp. $75-83,2000$.

[18] K. Strimbu and J. A. Tavel, "What are biomarkers?" Current Opinion in HIV \& AIDS, vol. 5, no. 6, pp. 463-466, 2010.

[19] C. Louvet, R. Labianca, P. Hammel et al., "Gemcitabine in combination with oxaliplatin compared with gemcitabine alone in locally advanced or metastatic pancreatic cancer: results of a GERCOR and GISCAD phase III trial," Journal of Clinical Oncology, vol. 23, no. 15, pp. 3509-3516, 2005.

[20] E. Van Cutsem, H. van de Velde, P. Karasek et al., "Phase III trial of gemcitabine plus tipifarnib compared with gemcitabine plus placebo in advanced pancreatic cancer," Journal of Clinical Oncology, vol. 22, no. 8, pp. 1430-1438, 2004.

[21] C. Vivaldi, C. Caparello, G. Musettini et al., "First-line treatment with FOLFOXIRI for advanced pancreatic cancer in clinical practice: patients' outcome and analysis of prognostic factors," International Journal of Cancer, vol. 139, no. 4, pp. 938-945, 2016.

[22] C. M. Kang, J. Y. Kim, G. H. Choi et al., "The use of adjusted preoperative CA 19-9 to predict the recurrence of resectable pancreatic cancer," Journal of Surgical Research, vol. 140, no. 1, pp. 31-35, 2007.

[23] S. K. Maithel, S. Maloney, C. Winston et al., "Preoperative CA 19-9 and the yield of staging laparoscopy in patients with radiographically resectable pancreatic adenocarcinoma," Annals of Surgical Oncology, vol. 15, no. 12, pp. 3512-3520, 2008.

[24] F. J. F. Engelken, V. Bettschart, M. Q. Rahman, R. W. Parks, and O. J. Garden, "Prognostic factors in the palliation of pancreatic cancer," European Journal of Surgical Oncology, vol. 29, no. 4, pp. 368-373, 2003.

[25] J. S. Falconer, K. C. H. Fearon, J. A. Ross et al., "Acute-phase protein response and survival duration of patients with pancreatic cancer," Cancer, vol. 75, no. 8, pp. 2077-2082, 1995.

[26] N. B. Jamieson, P. Glen, D. C. McMillan et al., "Systemic inflammatory response predicts outcome in patients undergoing resection for ductal adenocarcinoma head of pancreas," British Journal of Cancer, vol. 92, no. 1, pp. 21-23, 2005. 
[27] J. K. Pine, K. G. Fusai, R. Young et al., "Serum C-reactive protein concentration and the prognosis of ductal adenocarcinoma of the head of pancreas," European Journal of Surgical Oncology, vol. 35, no. 6, pp. 605-610, 2009.

[28] S. Mitsunaga, M. Ikeda, S. Shimizu et al., "C-reactive protein level is an indicator of the aggressiveness of advanced pancreatic cancer," Pancreas, vol. 45, no. 1, pp. 110-116, 2016.

[29] J. R. Infante, H. Matsubayashi, N. Sato et al., "Peritumoral fibroblast SPARC expression and patient outcome with resectable pancreatic adenocarcinoma," Journal of Clinical Oncology, vol. 25, no. 3, pp. 319-325, 2007.

[30] C. Gundewar, A. Sasor, K. S. Hilmersson, R. Andersson, and D. Ansari, "The role of SPARC expression in pancreatic cancer progression and patient survival," Scandinavian Journal of Gastroenterology, vol. 50, no. 9, pp. 1170-1174, 2015.

[31] M. Sinn, B. V. Sinn, J. K. Striefler et al., "SPARC expression in resected pancreatic cancer patients treated with gemcitabine: results from the CONKO-001 study," Annals of Oncology, vol. 25, no. 5, pp. 1025-1032, 2014.

[32] S. H. Shin, S. C. Kim, S.-M. Hong et al., "Genetic alterations of $\mathrm{K}$-ras, p53, c-erbB-2, and DPC4 in pancreatic ductal adenocarcinoma and their correlation with patient survival," Pancreas, vol. 42, no. 2, pp. 216-222, 2013.

[33] B. Bournet, F. Muscari, C. Buscail et al., "KRAS G12D mutation subtype is a prognostic factor for advanced pancreatic adenocarcinoma," Clinical and Translational Gastroenterology, vol. 7, article e157, 2016.

[34] K. Tjensvoll, M. Lapin, T. Buhl et al., "Clinical relevance of circulating KRAS mutated DNA in plasma from patients with advanced pancreatic cancer," Molecular Oncology, vol. 10, no. 4, pp. 635-643, 2016.

[35] H. Kinugasa, K. Nouso, K. Miyahara et al., "Detection of Kras gene mutation by liquid biopsy in patients with pancreatic cancer," Cancer, vol. 121, no. 13, pp. 2271-2280, 2015.

[36] J. A. DiGiuseppe, R. H. Hruban, S. N. Goodman et al., "Overexpression of $\mathrm{p} 53$ protein in adenocarcinoma of the pancreas," American Journal of Clinical Pathology, vol. 101, no. 6, pp. 684688, 1994.

[37] K. Mäkinen, T. Hakala, P. Lipponen, E. Alhava, and M. Eskelinen, "Clinical contribution of bcl-2, p53 and Ki-67 proteins in pancreatic ductal adenocarcinoma," Anticancer Research, vol. 18, no. 1, pp. 615-618, 1998.

[38] Y. Nio, M. Dong, C. Iguchi et al., "Expression of Bcl-2 and p53 protein in resectable invasive ductal carcinoma of the pancreas: effects on clinical outcome and efficacy of adjuvant chemotherapy," Journal of Surgical Oncology, vol. 76, no. 3, pp. 188-196, 2001.

[39] B. Gerdes, A. Ramaswamy, A. Ziegler et al., "p16INK4a is a prognostic marker in resected ductal pancreatic cancer: an analysis of p16INK4a, p53, MDM2, an Rb," Annals of Surgery, vol. 235, no. 1, pp. 51-59, 2002.

[40] J. Jeong, Y. N. Park, J. S. Park, D.-S. Yoon, H. S. Chi, and B. R. Kim, "Clinical significance of p16 protein expression loss and aberrant p53 protein expression in pancreatic cancer," Yonsei Medical Journal, vol. 46, no. 4, pp. 519-525, 2005.

[41] R. J. Bold, K. R. Hess, A. S. Pearson et al., "Prognostic factors in resectable pancreatic cancer: p53 and Bcl-2," Journal of Gastrointestinal Surgery, vol. 3, no. 3, pp. 263-277, 1999.

[42] J. Lundin, S. Nordling, K. Von Boguslawsky, P. J. Roberts, and C. Haglund, "Prognostic value of Ki-67 expression, ploidy and S-phase fraction in patients with pancreatic cancer," Anticancer Research, vol. 15, no. 6B, pp. 2659-2668, 1995.
[43] H. Kim, C. Y. Park, J. H. Lee, J. C. Kim, C. K. Cho, and H. J. Kim, "Ki-67 and p53 expression as a predictive marker for early postoperative recurrence in pancreatic head cancer," Annals of Surgical Treatment and Research, vol. 88, no. 4, pp. 200-207, 2015.

[44] Ö. Sagol, T. Yavuzşen, I. Öztop et al., “The effect of apoptotic activity, survivin, Ki-67, and P-glycoprotein expression on prognosis in pancreatic carcinoma," Pancreas, vol. 30, no. 4, pp. 343-348, 2005.

[45] K. J. Stanton, R. A. Sidner, G. A. Miller et al., "Analysis of Ki-67 antigen expression, DNA proliferative fraction, and survival in resected cancer of the pancreas," American Journal of Surgery, vol. 186, no. 5, pp. 486-492, 2003.

[46] H. Friess, Z. Lu, H. U. Graber et al., "Bax, but not bcl-2, influences the prognosis of human pancreatic cancer," Gut, vol. 43, no. 3, pp. 414-421, 1998.

[47] T. Naka, M. Kobayashi, K. Ashida, N. Toyota, T. Kaneko, and N. Kaibara, "Aberrant p16INK4 expression related to clinical stage and prognosis in patients with pancreatic cancer," International Journal of Oncology, vol. 12, no. 5, pp. 1111-1116, 1998.

[48] Y.-X. Hu, H. Watanabe, K. Ohtsubo et al., "Frequent loss of p16 expression and its correlation with clinicopathological parameters in pancreatic carcinoma," Clinical Cancer Research, vol. 3, no. 9, pp. 1473-1477, 1997.

[49] K. Ohtsubo, H. Watanabe, Y. Yamaguchi et al., "Abnormalities of tumor suppressor gene p16 in pancreatic carcinoma: immunohistochemical and genetic findings compared with clinicopathological parameters," Journal of Gastroenterology, vol. 38, no. 7, pp. 663-671, 2003.

[50] M. Tascilar, H. G. Skinner, C. Rosty et al., "The SMAD4 protein and prognosis of pancreatic ductal adenocarcinoma," Clinical Cancer Research, vol. 7, no. 12, pp. 4115-4121, 2001.

[51] A. V. Biankin, A. L. Morey, C.-S. Lee et al., "DPC4/Smad4 expression and outcome in pancreatic ductal adenocarcinoma," Journal of Clinical Oncology, vol. 20, no. 23, pp. 4531-4542, 2002.

[52] K. M. Murphy, K. A. Brune, C. Griffin et al., "Evaluation of candidate genes MAP2K4, MADH4, ACVR1B, and BRCA2 in familial pancreatic cancer: deleterious BRCA2 mutations in 17\%," Cancer Research, vol. 62, no. 13, pp. 3789-3793, 2002.

[53] K. Khan, D. Cunningham, C. Peckitt et al., "miR-21 expression and clinical outcome in locally advanced pancreatic cancer: exploratory analysis of the pancreatic cancer Erbitux, radiotherapy and UFT (PERU) trial," Oncotarget, vol. 7, no. 11, pp. 1267212681, 2016.

[54] N. Habbe, J.-B. M. Koorstra, J. T. Mendell et al., "MicroRNA miR-155 is a biomarker of early pancreatic neoplasia," Cancer Biology and Therapy, vol. 8, no. 4, pp. 340-346, 2009.

[55] Z. Xie, X. Chen, J. Li et al., "Salivary HOTAIR and PVT1 as novel biomarkers for early pancreatic cancer," Oncotarget, vol. 23, article 8323, 2016.

[56] J. Martinez-Useros, T. Georgiev-Hristov, A. Borrero-Palacios et al., "Identification of poor-outcome biliopancreatic carcinoma patients with two-marker signature based on ATF6 $\alpha$ and p-p38 'sTARD compliant"' Medicine, vol. 94, no. 45, Article ID e1972, 2015.

[57] Z. Niu, M. Wang, L. Zhou, L. Yao, Q. Liao, and Y. Zhao, "Elevated GRP78 expression is associated with poor prognosis in patients with pancreatic cancer," Scientific Reports, vol. 5, Article ID 16067, 2015. 
[58] A. Handra-Luca, S.-M. Hong, K. Walter, C. Wolfgang, R. Hruban, and M. Goggins, "Tumour epithelial vimentin expression and outcome of pancreatic ductal adenocarcinomas," British Journal of Cancer, vol. 104, no. 8, pp. 1296-1302, 2011.

[59] Y.-J. Li and X.-R. Ji, "Relationship between expression of Ecadherin-catenin complex and clinicopathologic characteristics of pancreatic cancer," World Journal of Gastroenterology, vol. 9, no. 2, pp. 368-372, 2003.

[60] S.-M. Hong, A. Li, K. Olino et al., "Loss of E-cadherin expression and outcome among patients with resectable pancreatic adenocarcinomas," Modern Pathology, vol. 24, no. 9, pp. 12371247, 2011.

[61] M. M. Oken, R. H. Creech, D. C. Tormey et al., "Toxicity and response criteria of the Eastern Cooperative Oncology Group," American Journal of Clinical Oncology, vol. 5, no. 6, pp. 649-655, 1982.

[62] K. S. Goonetilleke and A. K. Siriwardena, "Systematic review of carbohydrate antigen (CA 19-9) as a biochemical marker in the diagnosis of pancreatic cancer," European Journal of Surgical Oncology, vol. 33, no. 3, pp. 266-270, 2007.

[63] F. T. Bosman, F. Carneiro, R. H. Hruban, and N. D. Theise, Eds., World Health Organization Classification of Tumours of the Digestive System, IARC Press, Lyon, France, 2010.

[64] G. H. R. Klöppel, D. S. Longnecker, G. Adler, S. E. Kern, and T. J. Partanen, Ductal Adenocarcinoma of the Pancreas, World Health Organization Classification of Tumours. Pathology and Genetics of Tumours of the Digestive System, IARC Press, Lyon, France, 2000.

[65] J.-E. Kim, K. T. Lee, J. K. Lee, S. W. Paik, J. C. Rhee, and K. W. Choi, "Clinical usefulness of carbohydrate antigen 19-9 as a screening test for pancreatic cancer in an asymptomatic population," Journal of Gastroenterology and Hepatology, vol. 19, no. 2, pp. 182-186, 2004.

[66] S. Kawai, K. Suzuki, K. Nishio et al., "Smoking and serum CA19-9 levels according to Lewis and secretor genotypes," International Journal of Cancer, vol. 123, no. 12, pp. 2880-2884, 2008.

[67] M. J. Duffy, C. Sturgeon, R. Lamerz et al., "Tumor markers in pancreatic cancer: a European Group on Tumor Markers (EGTM) status report," Annals of Oncology, vol. 21, no. 3, pp. 441-447, 2010.

[68] D. Basso, C. Fabris, A. Meani et al., "C reactive protein in pancreatic cancer and chronic pancreatitis," Annals of Clinical Research, vol. 20, no. 6, pp. 414-416, 1988.

[69] J. Szkandera, M. Stotz, G. Absenger et al., "Validation of Creactive protein levels as a prognostic indicator for survival in a large cohort of pancreatic cancer patients," British Journal of Cancer, vol. 110, no. 1, pp. 183-188, 2014.

[70] K. Haruki, H. Shiba, Y. Shirai et al., "The C-reactive protein to albumin ratio predicts long-term outcomes in patients with pancreatic cancer after pancreatic resection," World Journal of Surgery, vol. 2016, article 8, 2016.

[71] W. Han, F. Cao, M.-B. Chen et al., "Prognostic value of SPARC in patients with pancreatic cancer: a systematic review and metaAnalysis," PLoS ONE, vol. 11, article e0145803, 2016.

[72] J. Vaz, D. Ansari, A. Sasor, and R. Andersson, "SPARC: a potential prognostic and therapeutic target in pancreatic cancer," Pancreas, vol. 44, no. 7, pp. 1024-1035, 2015.

[73] S. P. Thayer, M. P. di Magliano, P. W. Heiser et al., "Hedgehog is an early and late mediator of pancreatic cancer tumorigenesis," Nature, vol. 425, no. 6960, pp. 851-856, 2003.
[74] M. P. Di Magliano, S. Sekine, A. Ermilov, J. Ferris, A. A. Dlugosz, and M. Hebrok, "Hedgehog/Ras interactions regulate early stages of pancreatic cancer," Genes and Development, vol. 20, no. 22, pp. 3161-3173, 2006.

[75] C. Barceló, J. Etchin, M. R. Mansour et al., "Ribonucleoprotein HNRNPA2B1 interacts with and regulates oncogenic KRAS in pancreatic ductal adenocarcinoma cells," Gastroenterology, vol. 147, no. 4, pp. 882-892.e8, 2014.

[76] C. Almoguera, D. Shibata, K. Forrester, J. Martin, N. Arnheim, and M. Perucho, "Most human carcinomas of the exocrine pancreas contain mutant c-K-ras genes," Cell, vol. 53, no. 4, pp. 549-554, 1988.

[77] T. Deramaudt and A. K. Rustgi, "Mutant KRAS in the initiation of pancreatic cancer," Biochimica et Biophysica Acta-Reviews on Cancer, vol. 1756, no. 2, pp. 97-101, 2005.

[78] U.S. Food and Drug Administration, http://www.accessdata .fda.gov/scripts/cdrh/cfdocs/cfPMA/pma.cfm?start_search=1\& PMANumber=P140023.

[79] U.S._Food_and_Drug_Administration, http://www.accessdata .fda.gov/scripts/cdrh/cfdocs/cfPMA/pma.cfm?start_search=1\& PMANumber $=$ P110027.

[80] D. Gonzalez De Castro, B. Angulo, B. Gomez et al., "A comparison of three methods for detecting KRAS mutations in formalin-fixed colorectal cancer specimens," British Journal of Cancer, vol. 107, no. 2, pp. 345-351, 2012.

[81] Roche Diagnostics, cobas $^{\circledR}$ KRAS Mutation Test, 2012, http://www.accessdata.fda.gov/cdrh_docs/pdf14/P140023c.pdf.

[82] Qiagen, THERASCREEN ${ }^{\circledR}$ KRAS RGQ PCR, 2011, https://www .qiagen.com/us/landing-pages/therascreen-kras-test-usa-subgroups/.

[83] Qiagen, THERASCREEN ${ }^{\circledR}$ KRAS PYRO, 2010, https://www .qiagen.com/at/resources/resourcedetail?id=359d918e-6d544645-898f-f1846af9f18b\&lang=en.

[84] Qiagen, RAS EXTENSION PYRO V2, 2016, https://www .qiagen.com/us/shop/detection-solutions/personalized-healthcare/ras-ext-pyro-kit-row/\#resources.

[85] B. Bournet, C. Buscail, F. Muscari, P. Cordelier, and L. Buscail, "Targeting KRAS for diagnosis, prognosis, and treatment of pancreatic cancer: hopes and realities," European Journal of Cancer, vol. 54, pp. 75-83, 2016.

[86] E. Yonish-Rouach, D. Resnitzky, J. Lotem, L. Sachs, A. Kimchi, and M. Oren, "Wild-type p53 induces apoptosis of myeloid leukaemic cells that is inhibited by interleukin-6," Nature, vol. 352, no. 6333, pp. 345-347, 1991.

[87] D. Li, K. Xie, R. Wolff, and J. L. Abbruzzese, "Pancreatic cancer," The Lancet, vol. 363, no. 9414, pp. 1049-1057, 2004.

[88] R. H. Hruban, C. Iacobuzio-Donahue, R. E. Wilentz, M. Goggins, and S. E. Kern, "Molecular pathology of pancreatic cancer," Cancer Journal, vol. 7, no. 4, pp. 251-258, 2001.

[89] K. Wada, "p16 and p53 gene alterations and accumulations in the malignant evolution of intraductal papillary-mucinous tumors of the pancreas," Journal of Hepato-Biliary-Pancreatic Surgery, vol. 9, no. 1, pp. 76-85, 2002.

[90] S. T. Glenn, C. A. Jones, S. Sexton et al., "Conditional deletion of p53 and $\mathrm{Rb}$ in the renin-expressing compartment of the pancreas leads to a highly penetrant metastatic pancreatic neuroendocrine carcinoma," Oncogene, vol. 33, no. 50, pp. 5706-5715, 2014.

[91] B. Kong, T. Cheng, C. Qian et al., "Pancreas-specific activation of mTOR and loss of p53 induce tumors reminiscent of acinar cell carcinoma," Molecular Cancer, vol. 14, no. 1, article 212, 2015. 
[92] P. S. Moore, B. Sipos, S. Orlandini et al., "Genetic profile of 22 pancreatic carcinoma cell lines: analysis of K-ras, p53, p16 and DPC4/Smad4," Virchows Archiv, vol. 439, no. 6, pp. 798-802, 2001.

[93] Y. Nio, M. Dong, K. Uegaki et al., "Comparative significance of p53 and WAF/1-P21 expression on the efficacy of adjuvant chemotherapy for resectable invasive ductal carcinoma of the pancreas," Pancreas, vol. 18, no. 2, pp. 117-126, 1999.

[94] T. Scholzen and J. Gerdes, "The Ki-67 protein: from the known and the unknown," Journal of Cellular Physiology, vol. 182, no. 3, pp. 311-322, 2000.

[95] R. J. Bold, S. Virudachalam, and D. J. McConkey, "BCL2 expression correlates with metastatic potential in pancreatic cancer cell lines," Cancer, vol. 92, no. 5, pp. 1122-1129, 2001.

[96] M. Wu, C. Min, X. Wang et al., "Repression of BCL2 by the tumor suppressor activity of the lysyl oxidase propeptide inhibits transformed phenotype of lung and pancreatic cancer cells," Cancer Research, vol. 67, no. 13, pp. 6278-6285, 2007.

[97] J. Marx, "A challenge to p16 gene as a major tumor suppressor," Science, vol. 264, no. 5167, article 1846, 1994.

[98] L. Bonetta, "Tumor-suppressor genes. Open questions on p16," Nature, vol. 370, no. 6486, p. 180, 1994.

[99] C. Caldas, S. A. Hahn, L. T. de Costa et al., "Frequent somatic mutations and homozygous deletions of the p16 (MTS1) gene in pancreatic adenocarcinoma," Nature Genetics, vol. 8, no. 1, pp. 27-32, 1994.

[100] E. K. Duff and A. R. Clarke, "Smad4 (DPC4)—a potent tumour suppressor?" British Journal of Cancer, vol. 78, no. 12, pp. 1615$1619,1998$.

[101] S. A. Hahn, M. Schutte, A. T. M. Shamsul Hoque et al., "DPC4, a candidate tumor suppressor gene at human chromosome 18q21.1," Science, vol. 271, no. 5247, pp. 350-353, 1996.

[102] D. Maurice, C. E. Pierreux, M. Howell, R. E. Wilentz, M. J. Owen, and C. S. Hill, "Loss of Smad4 function in pancreatic tumors: C-terminal truncation leads to decreased stability," The Journal of Biological Chemistry, vol. 276, no. 46, pp. 43175-43181, 2001.

[103] H. Lodish, A. Berk, S. L. Zipursky, P. Matsudaira, D. Baltimore, and J. Darnell, Molecular Cell Biology, Section 24.4 Mutations Causing Loss of Cell-Cycle Control, W H Freeman, New York, NY, USA, 4th edition, 2000.

[104] Z.-H. Tang, S.-Q. Zou, Y.-H. Hao et al., "The relationship between loss expression of DPC4/Smad4 gene and carcinogenesis of pancreatobiliary carcinoma," Hepatobiliary and Pancreatic Diseases International, vol. 1, no. 4, pp. 624-629, 2002.

[105] M. Schutte, L. T. da Costa, S. A. Hahn et al., "Identification by representational difference analysis of a homozygous deletion in pancreatic carcinoma that lies within the BRCA2 region," Proceedings of the National Academy of Sciences of the United States of America, vol. 92, no. 13, pp. 5950-5954, 1995.

[106] C. Abaji, I. Cousineau, and A. Belmaaza, "BRCA2 regulates homologous recombination in response to DNA damage: implications for genome stability and carcinogenesis," Cancer Research, vol. 65, no. 10, pp. 4117-4125, 2005.

[107] M.-C. King, J. H. Marks, and J. B. Mandell, "Breast and Ovarian cancer risks due to inherited mutations in BRCA1 and BRCA2," Science, vol. 302, no. 5645, pp. 643-646, 2003.

[108] J. P. Struewing, P. Hartge, S. Wacholder et al., "The risk of cancer associated with specific mutations of BRCA1 and BRCA2 among Ashkenazi Jews," The New England Journal of Medicine, vol. 336, no. 20, pp. 1401-1408, 1997.
[109] S. A. Hahn, B. Greenhalf, I. Ellis et al., "BRCA2 germline mutations in familial pancreatic carcinoma," Journal of the National Cancer Institute, vol. 95, no. 3, pp. 214-221, 2003.

[110] M. Goggins, M. Sehutte, J. Lu et al., "Germline BRCA2 gene mutations in patients with apparently sporadic pancreatic carcinomas," Cancer Research, vol. 56, no. 23, pp. 5360-5364, 1996.

[111] M. Goggins, R. H. Hruban, and S. E. Kern, "BRCA2 is inactivated late in the development of pancreatic intraepithelial neoplasia: evidence and implications," The American Journal of Pathology, vol. 156, no. 5, pp. 1767-1771, 2000.

[112] M. Rowley, A. Ohashi, G. Mondal et al., "Inactivation of Brca2 promotes Trp53-associated but inhibits KrasG12D-dependent pancreatic cancer development in mice," Gastroenterology, vol. 140, no. 4, pp. 1303-1313, 2011.

[113] F. Skoulidis, L. D. Cassidy, V. Pisupati et al., "Germline Brca2 heterozygosity promotes KrasG12D -Driven carcinogenesis in a murine model of familial pancreatic cancer," Cancer Cell, vol. 18, no. 5, pp. 499-509, 2010.

[114] S. Morinaga, Y. Nakamura, Y. Atsumi et al., "Locked nucleic acid in situ hybridization analysis of MicroRNA-21 predicts clinical outcome in patients after resection for pancreatic cancer treated with adjuvant gemcitabine monotherapy," Anticancer Research, vol. 36, no. 3, pp. 1083-1088, 2016.

[115] X. Wei, W. Wang, L. Wang et al., "MicroRNA-21 induces 5fluorouracil resistance in human pancreatic cancer cells by regulating PTEN and PDCD4," Cancer Medicine, vol. 5, no. 4, pp. 693-702, 2016.

[116] M. Gironella, M. Seux, M.-J. Xie et al., "Tumor protein 53induced nuclear protein 1 expression is repressed by miR-155, and its restoration inhibits pancreatic tumor development," Proceedings of the National Academy of Sciences of the United States of America, vol. 104, no. 41, pp. 16170-16175, 2007.

[117] W. Pang, J. Su, Y. Wang et al., "Pancreatic cancer-secreted miR155 implicates in the conversion from normal fibroblasts to cancer-associated fibroblasts," Cancer Science, vol. 106, no. 10, pp. 1362-1369, 2015.

[118] Q. Ji, X. Hao, M. Zhang et al., "MicroRNA miR-34 inhibits human pancreatic cancer tumor-initiating cells," PLoS ONE, vol. 4, no. 8, Article ID e6816, 2009.

[119] F. Jiao, H. Hu, C. Yuan et al., "Elevated expression level of long noncoding RNA MALAT-1 facilitates cell growth, migration and invasion in pancreatic cancer," Oncology Reports, vol. 32, no. 6, pp. 2485-2492, 2014.

[120] F. Jiao, H. Hu, T. Han et al., "Long noncoding RNA MALAT-1 enhances stem cell-like phenotypes in pancreatic cancer cells," International Journal of Molecular Sciences, vol. 16, no. 4, pp. 6677-6693, 2015.

[121] X. Lu, Y. Fang, Z. Wang et al., "Downregulation of gas5 increases pancreatic cancer cell proliferation by regulating CDK6," Cell and Tissue Research, vol. 354, no. 3, pp. 891-896, 2013.

[122] N. A. Schultz, C. Dehlendorff, B. V. Jensen et al., "MicroRNA biomarkers in whole blood for detection of pancreatic cancer," The Journal of the American Medical Association, vol. 311, no. 4, pp. 392-404, 2014.

[123] S. Lust, B. Vanhoecke, M. Van Gele et al., "Xanthohumol activates the proapoptotic arm of the unfolded protein response in chronic lymphocytic leukemia," Anticancer Research, vol. 29, no. 10, pp. 3797-3805, 2009.

[124] S. Grant, "Enhancing proteotoxic stress as an anticancer strategy," Oncotarget, vol. 2, no. 4, pp. 284-286, 2011. 
[125] P. Workman and F. E. Davies, "A stressful life (or death): combinatorial proteotoxic approaches to cancer-selective therapeutic vulnerability," Oncotarget, vol. 2, no. 4, pp. 277-280, 2011.

[126] X. Chen, J. Shen, and R. Prywes, "The luminal domain of ATF6 senses endoplasmic reticulum (ER) stress and causes translocation of ATF6 from the er to the Golgi," The Journal of Biological Chemistry, vol. 277, no. 15, pp. 13045-13052, 2002.

[127] Y. Adachi, K. Yamamoto, T. Okada, H. Yoshida, A. Harada, and K. Mori, "ATF6 is a transcription factor specializing in the regulation of quality control proteins in the endoplasmic reticulum," Cell Structure and Function, vol. 33, no. 1, pp. 75-89, 2008.

[128] V. M. Parmar and M. Schröder, "Sensing endoplasmic reticulum stress," Advances in Experimental Medicine and Biology, vol. 738, pp. 153-168, 2012.

[129] J. M. Winter, C. J. Yeo, and J. R. Brody, "Diagnostic, prognostic, and predictive biomarkers in pancreatic cancer," Journal of Surgical Oncology, vol. 107, no. 1, pp. 15-22, 2013.

[130] A. S. Lee, "GRP78 induction in cancer: therapeutic and prognostic implications," Cancer Research, vol. 67, no. 8, pp. 34963499, 2007.

[131] J. B. Gifford, W. Huang, A. E. Zeleniak et al., "Expression of GRP78, master regulator of the unfolded protein response, increases chemoresistance in pancreatic ductal adenocarcinoma," Molecular Cancer Therapeutics, vol. 15, no. 5, pp. 10431052, 2016.

[132] R. Kalluri and R. A. Weinberg, "The basics of epithelial-mesenchymal transition," The Journal of Clinical Investigation, vol. 119, no. 6, pp. 1420-1428, 2009.

[133] Y. Masugi, K. Yamazaki, T. Hibi, K. Aiura, Y. Kitagawa, and M. Sakamoto, "Solitary cell infiltration is a novel indicator of poor prognosis and epithelial-mesenchymal transition in pancreatic cancer," Human Pathology, vol. 41, no. 8, pp. 1061-1068, 2010.

[134] A. D. Rhim, E. T. Mirek, N. M. Aiello et al., "EMT and dissemination precede pancreatic tumor formation," Cell, vol. 148, no. 1-2, pp. 349-361, 2012.

[135] B. Hotz, M. Arndt, S. Dullat, S. Bhargava, H.-J. Buhr, and H. G. Hotz, "Epithelial to mesenchymal transition: expression of the regulators snail, slug, and twist in pancreatic cancer," Clinical Cancer Research, vol. 13, no. 16, pp. 4769-4776, 2007.

[136] S. Guaita, I. Puig, C. Francí et al., "Snail induction of epithelial to mesenchymal transition in tumor cells is accompanied by MUC1 repression and ZEB1 expression," The Journal of Biological Chemistry, vol. 277, no. 42, pp. 39209-39216, 2002.

[137] J. Yang, S. A. Mani, J. L. Donaher et al., "Twist, a master regulator of morphogenesis, plays an essential role in tumor metastasis," Cell, vol. 117, no. 7, pp. 927-939, 2004.

[138] X. Zheng, J. L. Carstens, J. Kim et al., "Epithelial-to-mesenchymal transition is dispensable for metastasis but induces chemoresistance in pancreatic cancer," Nature, vol. 527, no. 7579, pp. 525-530, 2015.

[139] T. Arumugam, V. Ramachandran, K. F. Fournier et al., "Epithelial to mesenchymal transition contributes to drug resistance in pancreatic cancer," Cancer Research, vol. 69, no. 14, pp. 5820$5828,2009$.

[140] K. Zhang, X. Jiao, X. Liu et al., "Knockdown of snail sensitizes pancreatic cancer cells to chemotherapeutic agents and irradiation," International Journal of Molecular Sciences, vol. 11, no. 12, pp. 4891-4904, 2010.

[141] T. Yin, C. Wang, T. Liu, G. Zhao, Y. Zha, and M. Yang, "Expression of snail in pancreatic cancer promotes metastasis and chemoresistance," Journal of Surgical Research, vol. 141, no. 2, pp. 196-203, 2007.

[142] Z. Wang, Y. Li, D. Kong et al., "Acquisition of epithelial-mesenchymal transition phenotype of gemcitabine-resistant pancreatic cancer cells is linked with activation of the notch signaling pathway," Cancer Research, vol. 69, no. 6, pp. 2400-2407, 2009.

[143] M. Leader, M. Collins, J. Patel, and K. Henry, "Vimentin: an evaluation of its role as a tumour marker," Histopathology, vol. 11, no. 1, pp. 63-72, 1987.

[144] M. M. Javle, J. F. Gibbs, K. K. Iwata et al., "Epithelial-Mesenchymal Transition (EMT) and activated extracellular signalregulated kinase (p-Erk) in surgically resected pancreatic cancer," Annals of Surgical Oncology, vol. 14, no. 12, pp. 3527-3533, 2007.

[145] Y.-E. Joo, J.-S. Rew, C.-S. Park, and S.-J. Kim, "Expression of Ecadherin, alpha- and beta-catenins in patients with pancreatic adenocarcinoma," Pancreatology, vol. 2, no. 2, pp. 129-137, 2002.

[146] G. Klöppel, O. Basturk, A. M. Schlitter, B. Konukiewitz, and I. Esposito, "Intraductal neoplasms of the pancreas," Seminars in Diagnostic Pathology, vol. 31, no. 6, pp. 452-466, 2014.

[147] M. I. Canto, F. Harinck, R. H. Hruban et al., "International cancer of the pancreas screening (CAPS) consortium summit on the management of patients with increased risk for familial pancreatic cancer," Gut, vol. 62, no. 3, pp. 339-347, 2013.

[148] A. C. Berger, M. Garcia Jr., J. P. Hoffman et al., "Postresection CA 19-9 predicts overall survival in patients with pancreatic cancer treated with adjuvant chemoradiation: a prospective validation by RTOG 9704," Journal of Clinical Oncology, vol. 26, no. 36, pp. 5918-5922, 2008.

[149] M. J. Ferri, M. Saez, J. Figueras et al., "Improved pancreatic adenocarcinoma diagnosis in jaundiced and non-jaundiced pancreatic adenocarcinoma patients through the combination of routine clinical markers associated to pancreatic adenocarcinoma pathophysiology," PLoS ONE, vol. 11, no. 1, Article ID e0147214, 2016. 


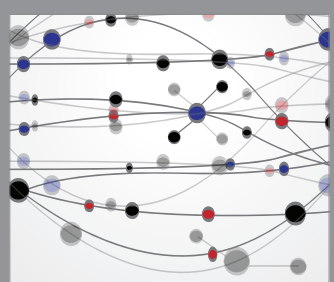

The Scientific World Journal
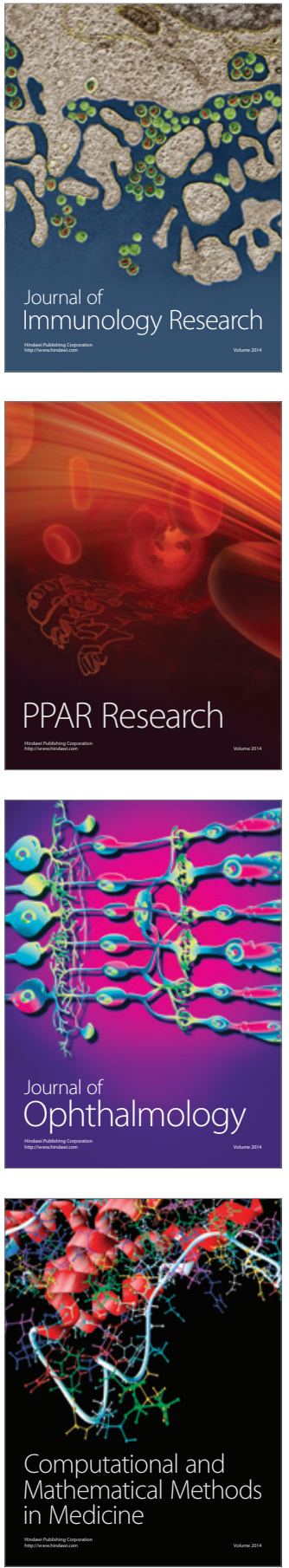

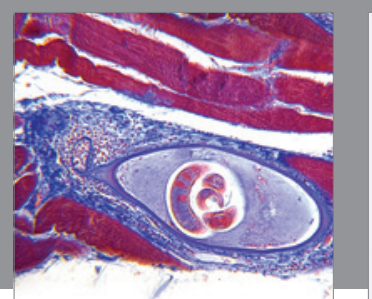

Gastroenterology Research and Practice

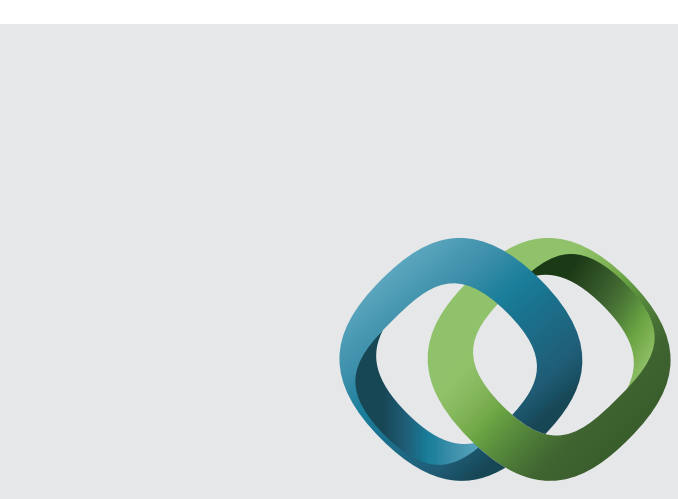

\section{Hindawi}

Submit your manuscripts at

http://www.hindawi.com
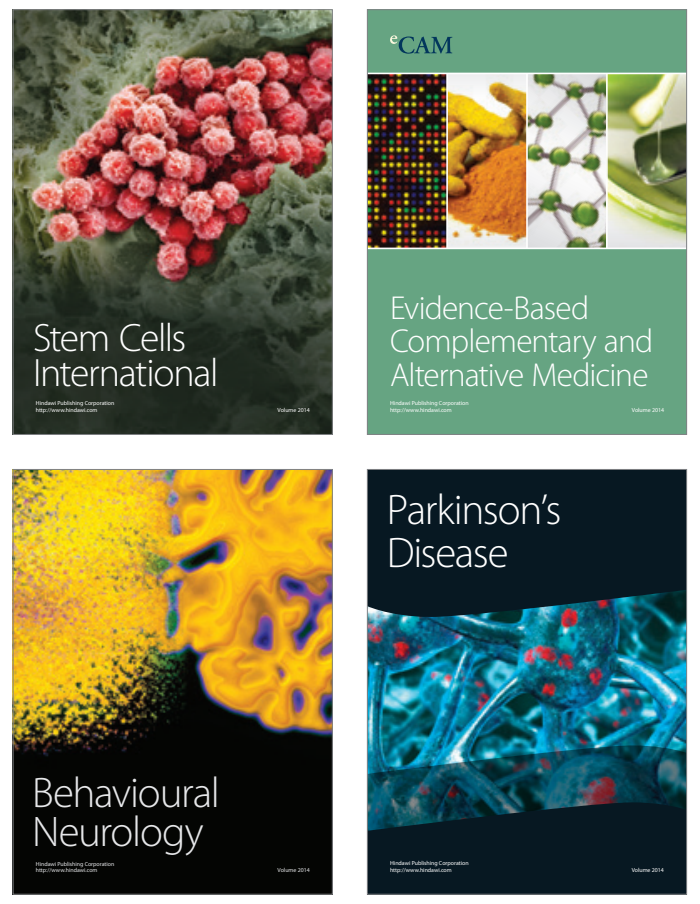
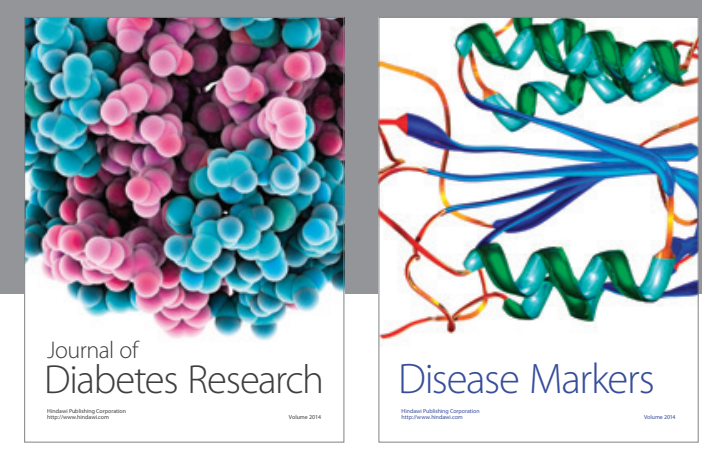

Disease Markers
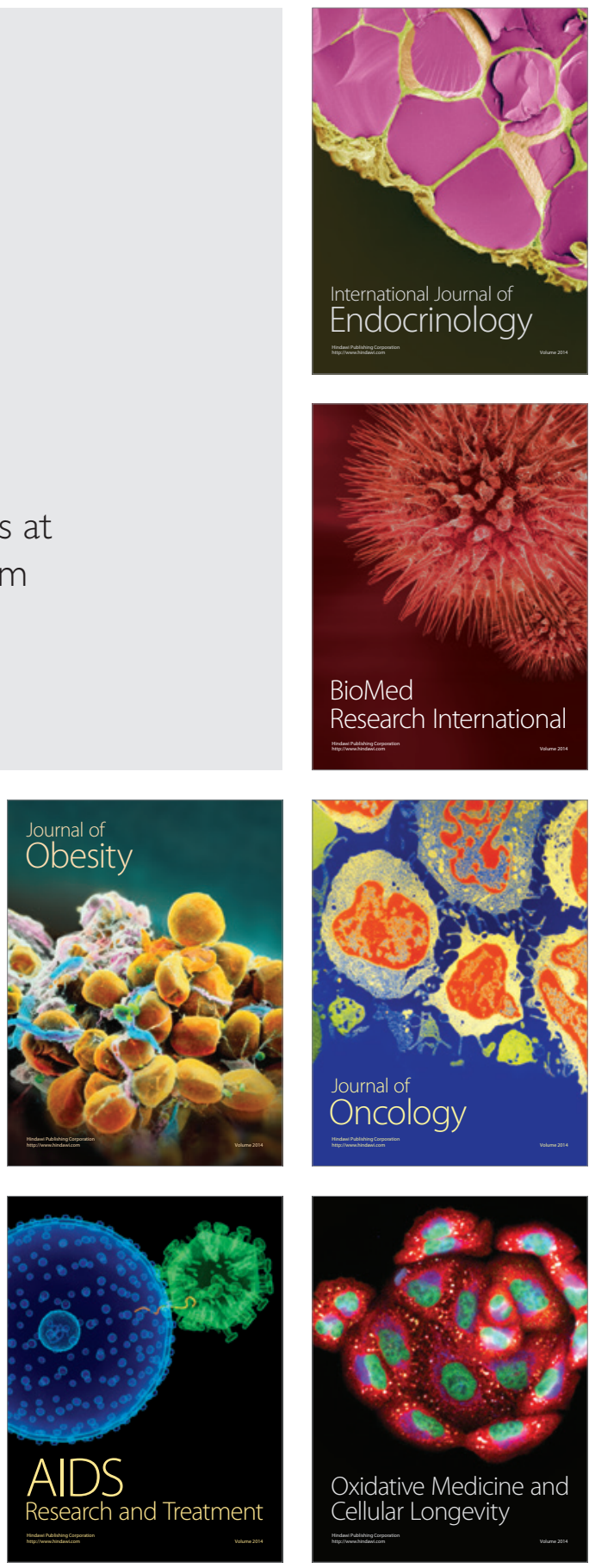